\title{
Su Şebeke Otomasyon Sistemi ve Uygulaması
}

\author{
Nazım IMAL ${ }^{1 *}$ \\ Geliş / Received: 28/05/2019 \\ Revize / Revised: 05/12/2019 \\ Kabul / Accepted: 16/03/2020
}

ÖZ

Geçmişten günümüze, suyu kaynağından alarak insanların kullanımına sunma, farklı uygulamalar ile gerçekleştirilmiştir. Makine ve elektrik sistemlerinin geliştirilmesi, öncesine nazaran insanlara çok daha temiz ve bol su temin eden su şebekelerini mümkün kılmıştır. Elektrik ve otomatik su kontrol sistemleri, kapalı devre su sistemlerinin kullanılmaya başladığı birkaç yüzyıl öncesinden bu yana kullanılmaktadır. Otomatik su sistemleri, geçmişte sadece vana ve şamandıralı olarak gerçekleşirken, gelişen teknoloji ile birlikte basınç şalterleri ve sensör teknolojileri ile tasarlanmaya başlamıştır. Su otomasyonunda kullanılan sensörler; 1şıklı ve ultrasonik sensörler olabileceği gibi elektriksel sızıntı akımlarının kullanıldığı seviye algılayıcıları da olabilir. Burada gerçekleştirilen çalışmada; kuyu, depo ve hidrofor tankına ait üçlü model için elektrot algılayıcılar kullanılarak, su şebeke otomasyonu gerçekleştirilmiştir. Gerçekleştirilen otomasyonda çıktı olarak abonelere verilen suyun kesintisizliği dikkate alınmakla beraber, suyun sağlanmasında oluşabilecek yetersizlikler de belirleyici etken olmaktadır. Tasarlanan otomasyon sisteminin; kuyu, depo ve tank olarak üçlü kombinasyon ile gerçekleştirilmesi, suyun kaynağından son çıkış noktasına kadar abonelere kontrollü akışını mümkün kılmaktadır. Su yetersizliği durumunda, su akışlarının kesilmesi öncesi uyarı sisteminin de mevcut olması, sistemin ekstra avantajını oluşturmaktadır.

Anahtar Kelimeler-Su şebekesi, Kontrol, Otomasyon

1*Sorumlu yazar iletişim: nazim.imal@bilecik.edu.tr (https://orcid.org/0000-0002-8592-0281)

Elektrik Elektronik Mühendisliği,Mühendislik Fakültesi, Bilecik Şeyh Edebali Üniversitesi, Bilecik 


\title{
Water Network Automation System and Application
}

\begin{abstract}
From past to present, taking water from its source and making it available to people has been realized with different applications. The development of machinery and electrical systems has enabled water networks to provide people with much cleaner and more abundant water than before. Electrical and automatic water control systems have been in use since several centuries before closed-circuit water systems began to be used. In the past, automatic water systems only design with valves and floats, they have been started to be designed with pressure switches and sensor technologies by developing technology. Sensors used in water automation can be light or ultrasonic sensors, they can also level sensors using electrical leakage currents. In this study, water network automation was realized by using electrode sensors for triple model of well, tank and pressure tank. In the automation realized as output, the continuity of the water supplied to the subscribers is taken into consideration, also deficiencies in the provision of water are determining factors. Implementation of the designed automation system in three combinations as well, store and tank, it enables controlled flow of water to its subscribers from its source to its final outlet. In case of insufficient water, also the presence of a warning system before the interruption of water flows is an extra advantage of the designed system.
\end{abstract}

Keywords- Water network, Control, Automation 


\section{GİRIŞ}

Su şebekeleri, suyu doğal kaynağından temin ederek, ön depolama işlemi sonrası kullanıcılara ileten akışkan taşıma sistemlerdir. Doğal kaynağından cebri yöntemlerle çekilen su, filtreleme ve dinlendirme aşamaları için depolara iletilir. Depolarda bekletilen kullanıma hazır suyun abonelere ulaşabilmesi, basıncı yeterli ise direkt olarak, basıncı yetersiz olduğunda ise (çoğu kez olduğu gibi) basıncının arttırılması ile gerçekleşir. Bu amaçla, depodan çıkan su hidrofor sisteminden geçirilerek, basınçlı hale getirilir.

Yapılan çalışmada, şekil 1'de görülen doğal kaynak, depo ve hidrofor sistemi tümleşik olarak kullanılarak, mikroişlemci kontrollü su otomasyon sistemi prototipi gerçekleştirilmiş̧ir. Yapılan tasarımda, üçlü kombinasyonun her birisi için, sistemin normal çalışmasında gerekli minimum su seviyesi dikkate alındığı gibi, maksimum seviye sınırlamaları ile aşırı süreli ve fazla start stoplu çalışmanın önüne geçilmiş̧ir. Sistemin ayrı ayrı ele alınması yerine, doğal kaynak, depo ve hidrofor bileşimi üçlü kombinasyon olarak dikkate alınması benzer sistemlerden farkını meydana getirmektedir. Geliştirilen sistem, bakımları yapılması şartıyla, su kaynağı yeterli olduğu müddetçe sorunsuz çalışabilme yeteneğine sahiptir. Sistem su akışını tam kontrollü hale getirdiğinden, sistem kaynaklı su kayıplarının da önüne geçilmektedir.

Çalışmanın ana kontrol ünitesi için mikro denetleyicili bir kontrol sistemi kullanılmıştır. Sistemin tasarımında ve uygulama aşamasında sunduğu kolaylıklar nedeniyle çalışmada PIC 16F877 mikro denetleyicisi kullanılarak, denetleyici yazılımı C dilinde hazırlanmıştır. Hazırlanan yazılım mikro denetleyiciye, PC'nin seri portu aracılığıyla PICPROG yazılımı ile yüklenmiştir.

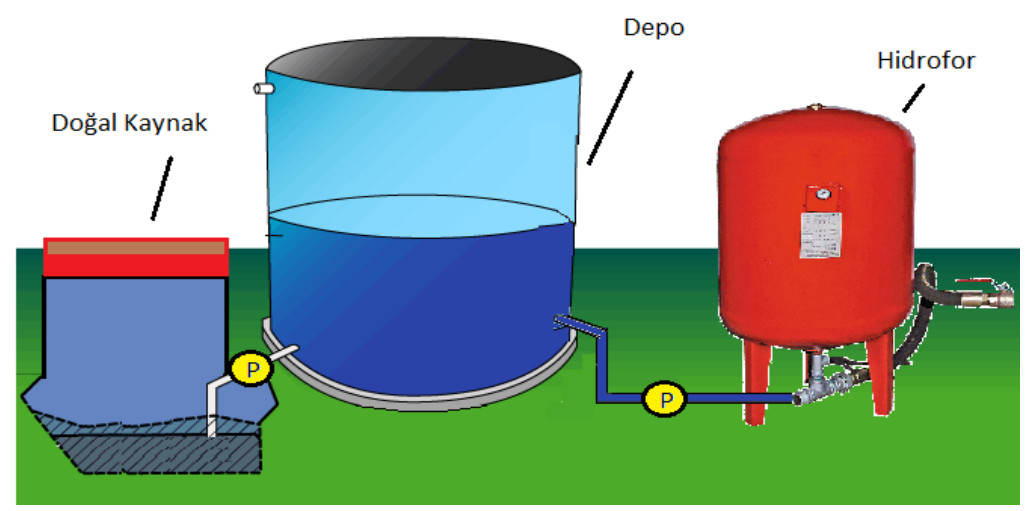

Şekil 1. Doğal kaynak, depo ve hidrofor kombinasyonu

Çalışma kapsamındaki daha önce yapılan çalışmalar incelendiğinde, Gregory ve Atkins'in 1988 yılında, Lenker ve arkadaşlarının ise 2002 yılında gerçekleştirdikleri çalışmalarında, otomatik su temini ve kontrolü üzerinde durdukları görülmüştür. Bu çalışmalar, su otomasyonu ve kontrolünde gerekli olan parametreler bakımından faydalı olmuştur. Olsson 2007 yılındaki çalışmasında, temiz ve atık su sistemlerinde kullanılan otomasyon yöntemlerinden, Das ve arkadaşları 2013 yılında, Brakel ve arkadaşları ise 2015 yılında gerçekleştirdikleri çalışmalarında, su ve akışkan kontrolünde kullanılan modern kontrol teknikleri üzerinde durmuşlardır. Bu çalışmalar ise, günümüz su otomasyonu için gerekli modern kriterler bakımından faydalı olmuştur.

\section{SU ŞEBEKE OTOMASYON SISTEMİ}

Su şebekesi otomatik kontrol sistemi, sekil 2'deki uygulama modelinde görüldüğü gibi; doğal depo, dinlendirme deposu ve hidrofor deposunun yer aldığı kombine bir yapıya sahiptir. Tüm depo birimleri, içerisinde yer alan sıvı seviyelerini algılama özellikli elektrotlara sahiptir. Bu elektrotlardan en altta yer alan elektrotlar, her üç depo içinde referans elektrotu özelliği taşımakta olup, toprak potansiyelinin karşıllığı olarak $0 \mathrm{~V}$ potansiyeline sahiptir. Diğer elektrotlar ise minimum ve maksimum su seviyesini algılama özelliklidirler [1,3]. 
Elektrotlar ile depolardan elde edilen su seviye algılama verileri, kontrol katında yer alan mikroişlemci algılamaları ile kontrol edilerek sürücü katı ile M1 ve M2 motorlarını çalıştırmaktadır. M1 motoru doğal depodan suyu dinlendirme deposuna taşıyan pompayı çalıştırırken, M2 motoru ise dinlendirme deposunda dinlenmiş olan suyu hidrofor tankına taşıyan pompayı çalıştırmaktadır $[7,8,9,10,11,12]$.

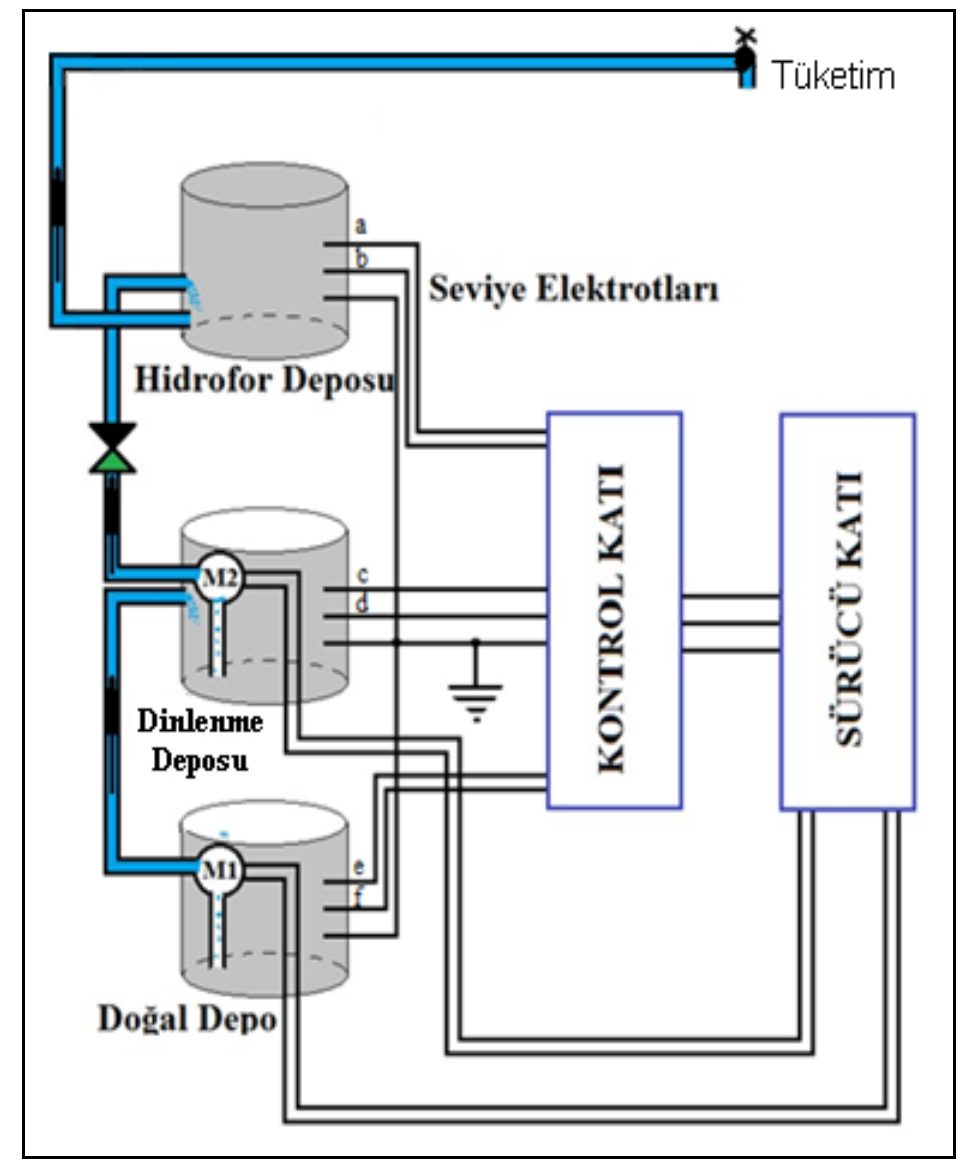

Şekil 2. Su şebekesi, otomatik kontrol sistemi modeli

Otomasyon ve kontrol sistemlerinin üzerinde geliştirildiği üç depolu prototip sistem ise şekil 3'de görülmektedir. Burada, minyatür bir prototip sağlayabilmek için; depo olarak plastik kaplar, pompa ve motor sistemleri olarak otomobiller için kullanılan yağmur suyu DC motorları, algılayıcı olarak da depo kaplara yaklaşık $1 \mathrm{~cm}$ kadar batırılmış, özel bir yapısal özelliği olmayan metal vida elektrotlar kullanılmıştır.

Doğal depo ve dinlendirme deposu atmosfer basıncına açık durumda iken, hidrofor tankında ekstra basınç sağlanabilmesi için tamamen kapalı tercih edilmiştir [15,18]. Hidrofor tankında yeterli basınçta su birikimi mevcutken M2 motoru durduğunda, suyun ters yöne tahliye olmaması için, suyun ters yöne akışını engelleyici bir çek valf kullanılmıştır.

Şekil 4'de ise, M1 ve M2 motorlarını çalıştıran mikroişlemci temelli kontrol ve güç katı şeması görülmektedir [13, 14, 16]. Devrede, röleler için gerekli olan 20 mA'lik 25 mA'lik mikroişlemci çıkışı yeterli olsa da, iki adet rölenin sürümü gerektiğinden $20 \mathrm{~mA}$ çıkışı bulunan BD737 transistorları, röleleri sürebilecek 
yeterlilikte akımı sağlamaktadırlar. M1 ve M2 motorlarının çektiği çok daha büyük değerli akımlar ise röleler üzerinden verilmektedir.

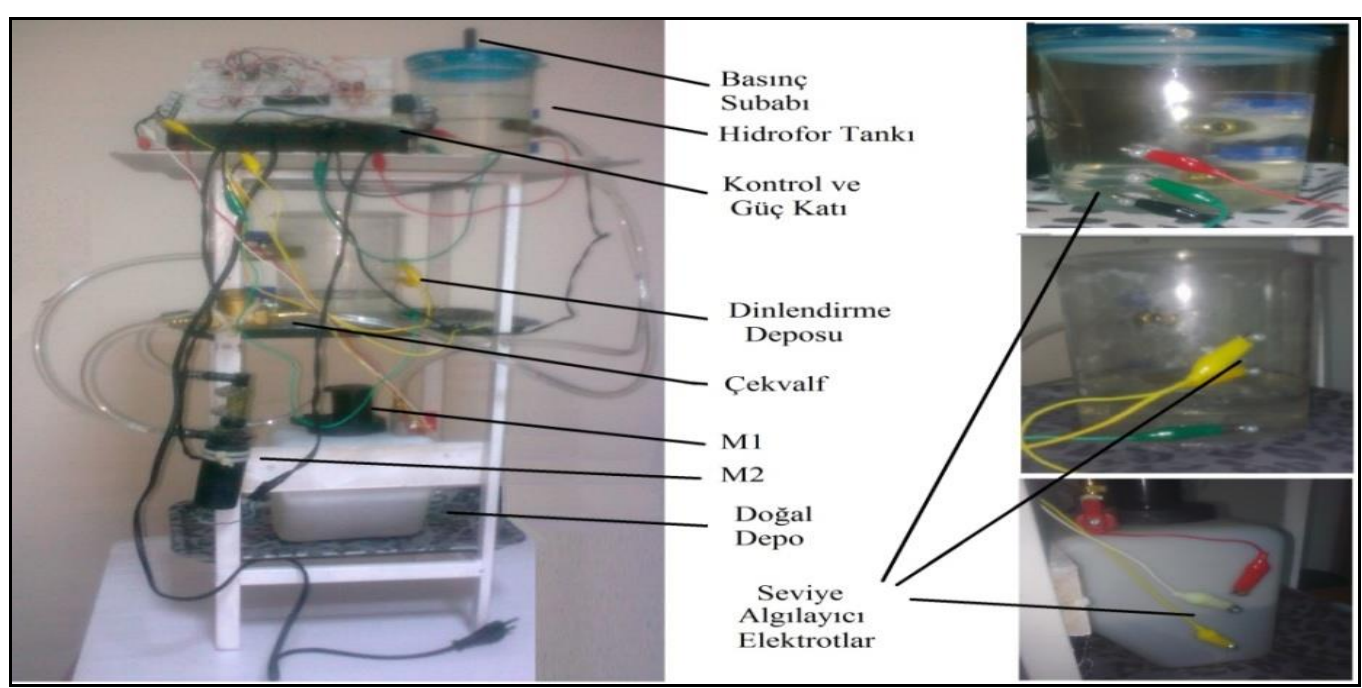

Şekil 3. Su şebekesi, otomatik kontrol sistemi uygulama şeması

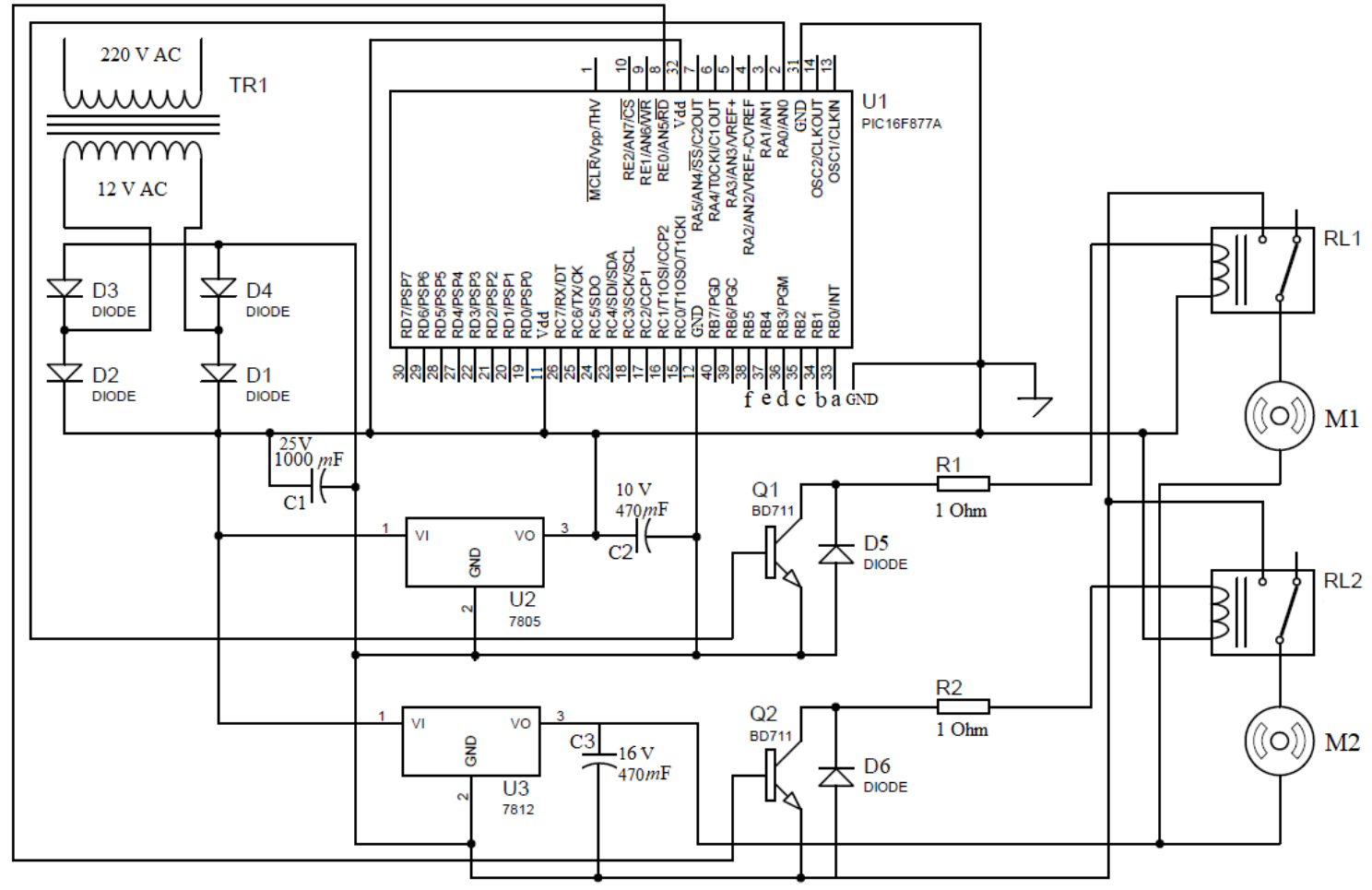

Şekil 4. Kontrol ve güç devresi 


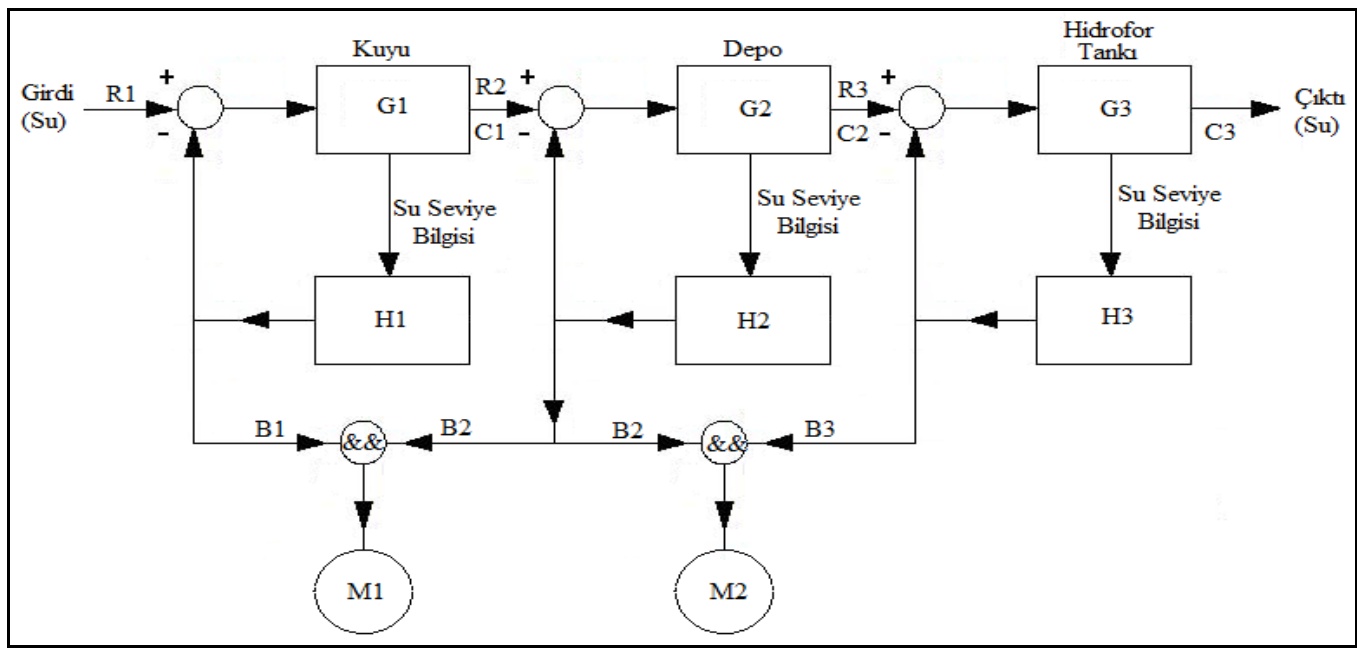

Şekil 5. Kontrol şemas

\section{SİSTEMIN ÇALIŞMASI}

Otomatik kontrollü su şebekesinin çalıştırılabilmesi için, şekil 4'de görülen kontrol devresinin şekil 5'de görülen kontrol akış şemasına uygun olarak kumanda edilmesi gerekir [2, 4, 5, 6, 9,10]. Böylece, üç depolu sistemde su akış ve kombinasyonun, en uygun biçimde gerçekleştirilmesi sağlanmış olur [17, 19]. Sistemde yeterli su sağlanması amaç olduğu gibi, minimum ve maksimum limit seviyelerine uyulması zorunluluğu da mevcuttur. Kontrol akış şemasında girdi ve çıktı, sistemin kuruluş amacına uygun olarak, su miktarı tarzında görülmektedir. Şekil 5'de görülen kontrol şemasına uygun olarak sistemin ara çıktıları;

$$
\begin{aligned}
& \mathrm{C} 1=\frac{\mathrm{G} 1 \cdot \mathrm{R} 1}{1+\mathrm{G} 1 \cdot \mathrm{H} 1} \\
& \mathrm{C} 2=\frac{\mathrm{G} 2 \cdot \mathrm{R} 2}{1+\mathrm{G} 2 \cdot \mathrm{H} 2} \\
& \mathrm{C} 3=\frac{\mathrm{G} 3 \cdot \mathrm{R} 3}{1+\mathrm{G} 3 \cdot \mathrm{H} 3}
\end{aligned}
$$

olarak yazılabilir. Birinci sistemin ara çıtısını, ikinci sistemin girdisi olarak ele alırsak, ikinci sistem dahil olan sistem çıktısı;

$$
\begin{aligned}
\mathrm{C} 2 & =\frac{\mathrm{G} 2 \cdot \frac{\mathrm{G} 1 \cdot \mathrm{R} 1}{1+\mathrm{G} 1 \cdot \mathrm{H} 1}}{1+\mathrm{G} 2 \cdot \mathrm{H} 2} \\
\mathrm{C} 2 & =\frac{\mathrm{G} 1 \cdot \mathrm{G} 2 \cdot \mathrm{R} 1}{(1+\mathrm{G} 1 \cdot \mathrm{H} 1) \cdot(1+\mathrm{G} 2 \mathrm{H} 2)}
\end{aligned}
$$

olarak eşitlik (5) olarak yazılabilir. Birinci ve ikinci sistemin ara çıktısını üçüncü sistemin girdisi olarak ele alırsak, tüm sistemin çıktısı; 


$$
\begin{aligned}
\mathrm{C} 3 & =\frac{\mathrm{G} 3 \cdot \frac{\mathrm{G} 1 \cdot \mathrm{G} 2 \cdot \mathrm{R} 1}{(1+\mathrm{G} 1 \cdot \mathrm{H} 1) \cdot(1+\mathrm{G} 2 \mathrm{H} 2)}}{1+\mathrm{G} 3 \cdot \mathrm{H} 3} \\
\mathrm{C} 3 & =\frac{\mathrm{G} 1 \cdot \mathrm{G} 2 \cdot \mathrm{G} 3 \cdot \mathrm{R} 1}{(1+\mathrm{G} 1 \cdot \mathrm{H} 1) \cdot(1+\mathrm{G} 2 \mathrm{H} 2)(1+\mathrm{G} 3 \mathrm{H} 3)}
\end{aligned}
$$

olarak yazılabilir. Buradan tüm sistemin transfer fonksiyonu eşitlik (8)'deki gibi ifade edilirse;

$$
\begin{aligned}
& \mathrm{TF}=\frac{\mathrm{C} 3}{\mathrm{R} 1} \\
& \mathrm{TF}=\frac{\frac{\mathrm{G} 1 \cdot \mathrm{G} 2 \cdot \mathrm{G} 3 \cdot \mathrm{R} 1}{(1+\mathrm{G} 1 \cdot \mathrm{H} 1) \cdot(1+\mathrm{G} 2 \mathrm{H} 2)(1+\mathrm{G} 3 \mathrm{H} 3)}}{\mathrm{R} 1} \\
& \mathrm{TF}=\frac{\mathrm{G} 1 \cdot \mathrm{G} 2 \cdot \mathrm{G} 3}{(1+\mathrm{G} 1 \cdot \mathrm{H} 1) \cdot(1+\mathrm{G} 2 \mathrm{H} 2)(1+\mathrm{G} 3 \mathrm{H} 3)}
\end{aligned}
$$

olarak eşitlik (10) daki gibi sistemin transfer fonksiyonu yazılır. Sistemden alınan seviye verilerinin geri yönlü değerlendirilmesi ile M1 ve M2 pompa motorlarının çalışma durumlarına karar verilmektedir. Kontrol akış şemasına uygun olarak M1 ve M2 pompa motorlarının ne zaman çalışıp, duracaklarına, eşitlik (11) ve (12)'de görüldüğü gibi, seviye bilgilerinin değerlendirilmesi ile kontrol ve güç katı karar vermektedir. Bu eşitliklerden de anlaşılacağı gibi, M1 ve M2 pompa motorları, şekil 5'deki kontrol akış bilgileri “1” olduğunda çalışmaktadırlar.

$$
\begin{aligned}
& \mathrm{M} 1=\mathrm{C} 1 \cdot \mathrm{H} 1 \cdot \mathrm{C} 2 \cdot \mathrm{H} 2 \\
& \mathrm{M} 2=\mathrm{C} 2 \cdot \mathrm{H} 2 \cdot \mathrm{C} 3 \cdot \mathrm{H} 3
\end{aligned}
$$

M1 ve M2 motorlarının çalışabilmeleri eşitliklerdeki tüm bilgilerin "1" olması şartıyla mümkün olmaktadır. Sistemin çalışma algoritmasına uygun olarak, M1 ve M2 motorları için yazılan ve kontrol katında 16F877 nolu mikrodenetleyiciye kodları aktarılan yazılımın akış şeması ise şekil 6'da görülmektedir. M1 ve M2 motorları için farklı algılama durumlarındaki farklı doğruluk tabloları ise tablo 1 ve tablo 2'de görülmektedir.

Üç depolu sistemde, M1 ve M2 pompa motorları, kontrol akış şeması ve doğruluk tablolarına uygun olarak, doğal depodan aldığı suyu tüketime sunmaktadır. Tablo 1 ve tablo 2'de yer alan M1, M2 verileri, pompa motorlarının mevcut çalışma yada çalışmama durumunu; $\mathrm{M} 1_{\text {out }}, \mathrm{M} 2_{\text {out }}$ verileri ise pompa motorları için kontrol sistemi tarafından elde edilen yeni çalışma yada çalışmama durumunu göstermektedir.

. Doğal depoda su "f” elektrotunun altında olduğunda M1 pompa motoru çalışmayacaktır. Su seviyesi yeterli miktarda artarak "e" elektrotuna ulaştığında, doğal depodan gelen veri M1 pompa motorunun çalışması için gerekli izni sağlasa da, bu durumda dinlendirme su deposundaki su seviyesi önem kazanacaktır. Dinlendirme su deposunda su seviyesi " $d$ " elektrotunun altında ise M1 pompa motoru çalışacak ve su seviyesi "c" elektrotuna ulaştığında duracaktır. Su seviyesi "d" elektrotunun altına düşene kadar dinlendirme deposundan M1 pompa motorunun çalışması için olumlu veri sağlanmayacaktır.

Dinlendirme deposunda su "d" elektrotunun altında olduğunda M2 pompa motoru çalışmayacaktır. Su seviyesi yeterli miktarda artarak "c" elektrotuna ulaştığında, dinlendirme deposundan gelen veri M2 pompa motorunun çalışması için gerekli izni sağlasa da, bu durumda hidrofor su deposundaki su seviyesi önem kazanacaktır. Hidrofor su deposunda su seviyesi "b" elektrotunun altında ise M1 pompa motoru çalışacak ve su seviyesi "a" elektrotuna ulaştığında duracaktır. Su seviyesi "b" elektrotunun altına düşene kadar hidrofor deposundan M2 pompa motorunun çalışması için olumlu veri sağlanmayacaktır. 


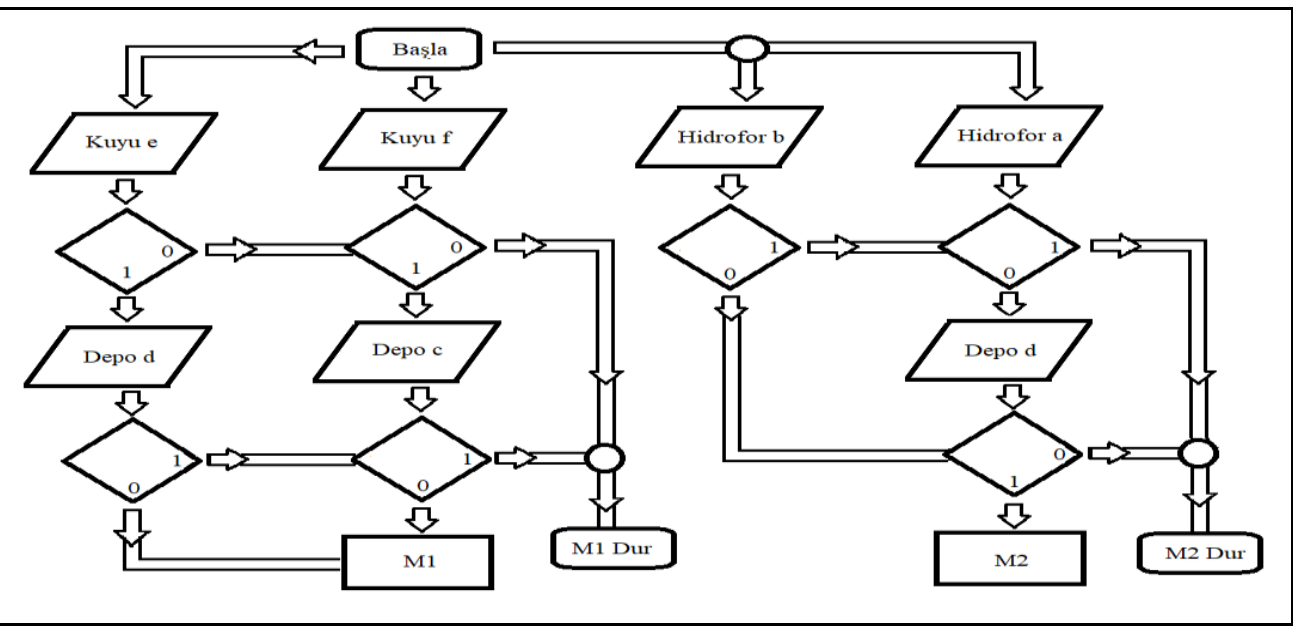

Şekil 6. Yazılım akışşeması

Tablo 1. M1 motoru doğruluk tablosu

\begin{tabular}{cccccc}
\hline M1 & $\mathrm{c}$ & $\mathrm{d}$ & $\mathrm{e}$ & $\mathrm{f}$ & $\mathrm{M} 1_{\text {out }}$ \\
\hline 0 & 0 & 0 & 0 & 0 & 0 \\
0 & 0 & 0 & 0 & 0 & 0 \\
0 & 0 & 0 & 0 & 1 & 0 \\
0 & 0 & 0 & 1 & 1 & 1 \\
0 & 0 & 1 & 0 & 0 & 0 \\
0 & 0 & 1 & 0 & 1 & 0 \\
0 & 0 & 1 & 1 & 1 & 1 \\
0 & 1 & 1 & 0 & 0 & 0 \\
0 & 1 & 1 & 0 & 1 & 0 \\
0 & 1 & 1 & 1 & 1 & 0 \\
1 & 0 & 0 & 0 & 1 & 1 \\
1 & 0 & 0 & 1 & 1 & 1 \\
1 & 0 & 1 & 0 & 0 & 0 \\
1 & 0 & 1 & 0 & 1 & 1 \\
1 & 0 & 1 & 1 & 1 & 1 \\
1 & 1 & 1 & 0 & 0 & 0 \\
1 & 1 & 1 & 0 & 1 & 0 \\
1 & 1 & 1 & 1 & 1 & 0 \\
\hline
\end{tabular}

Tablo 2. M2 motoru doğruluk tablosu

\begin{tabular}{cccccc}
\hline M2 & $\mathrm{c}$ & $\mathrm{d}$ & $\mathrm{a}$ & $\mathrm{b}$ & $\mathrm{M} 2_{\text {out }}$ \\
\hline 0 & 0 & 0 & 0 & 0 & 0 \\
1 & 0 & 1 & 0 & 0 & 1 \\
1 & 1 & 1 & 0 & 0 & 1 \\
1 & 0 & 0 & 0 & 1 & 0 \\
1 & 0 & 1 & 0 & 1 & 1 \\
1 & 1 & 1 & 0 & 1 & 1 \\
1 & 0 & 0 & 1 & 1 & 0 \\
1 & 0 & 1 & 1 & 1 & 0 \\
1 & 1 & 1 & 1 & 1 & 0 \\
0 & 0 & 0 & 0 & 0 & 0 \\
0 & 0 & 1 & 0 & 0 & 0 \\
0 & 1 & 1 & 0 & 0 & 1 \\
0 & 0 & 0 & 0 & 1 & 0 \\
0 & 0 & 1 & 0 & 1 & 0 \\
0 & 1 & 1 & 0 & 1 & 1 \\
0 & 0 & 0 & 1 & 1 & 0 \\
0 & 0 & 1 & 1 & 1 & 0 \\
0 & 1 & 1 & 1 & 1 & 0 \\
\hline
\end{tabular}




\section{SONUÇLAR}

Su şebekesi, otomatik kontrol sistemi uygulamasında kuyu, nehir, göl v.b. doğal su kaynakları, doğal depo olarak tanımlanmış ve uygulamada da bu biçimde gösterilmiştir. Gerçek uygulamaların birçoğunda olduğu gibi doğal depodan alınan su dinlenme deposuna, buradan da tüketiciler için kullanım basıncının sağlandığ hidrofor deposuna iletilmiştir. Böylece, kaynağından son tüketim yerine kadar, su taşıma ve tesislerinin benzerliği sağlanabilmiştir. Gerçek uygulamalarda; kuyu yada su kaynağının, depo ve hidrofor sistemine uzaklığı farklı olabilirken, depo ve hidrofor sistemi genellikle birbirine yakın olmaktadır. Tasarlanan modelde, birbirlerinden uzak olmaları daha uzun boru ve iletken kullanımını gerektireceğinden üç birimin de birbirine yakın olması tercih edilmiştir. Su kaynağı, depo ve hidroforun birbirlerine uzak olmaları daha büyük motor güçleri gerektirse de, kontrol ve otomasyon bakımından bir fark oluşturmamaktadır. Tasarlanan sistemin enerji verimliliği bakımından ayrıca bir analizi yapılmamış olmakla beraber; su kaynağı, depo ve hidroforun en optimum biçimde çalışmasını yada çalışmamasını sağlayacağından enerji verimliliğine katkı sağlayacağı öngörülmektedir. Tasarlanılan sistemin, enerji verimliliği kapsamında değerlendirilmesi ayrı bir çalışma ile ele alınmalıdır.

Üç depolu olarak gerçekleştirilen uygulamada, tüm depolar için su seviyesinin minimum su seviyesinin altına düşmemesi ve maksimum su seviyesinin üstüne çıkmaması amaçlanmıştır. Farklı yöntemlerle de sağlanabilecek su seviye algılamaları için burada, elektrotlu algılama sistemi tercih edilmiştir. Su içerisindeki tuz ve eriyikler bir miktar elektriksel iletkenlik sağladığından, su miktarının algılanması, su seviyesi algılayıcı elektrotlar ile gerçekleştirilmiştir. Su seviyesi algılayıcı elektrotlar ile kuyuda ve depoda suyun aşırı azalması ve artmasının önüne geçilmesi hedeflenmiştir. Hidrofor tankında ise bu işlem, basıncın aşırı azalması ve artmasının önüne geçilmesi amaçlı gerçekleştirilmiştir. Su seviyesi algılayıcı elektrotlardan elde edilen verileri değerlendirme doğrultusunda; kontrol şeması, kontrol şemasına uygun kod yazılımı ve tasarlanan tüm sistem için prototip uygulama gerçekleştirilmiştir. Gerçekleştirilen uygulama ile çok geniş ve yaygın ortamlarda mevcut olan benzer sistemlerin bir bütün olarak modellenmesi sağlanmıştır. Sistemde elde edilen veriler, mikrodenetleyici kontrolü ve güç katı ile pompa motorlarının çalışıp çalışmamasına etki etmektedir. Sistem, dış müdahale gerektirmeyen, tam otomatik ve bağımsız çalışma gerçekleştirebilecek biçimde tasarlanmıştır. İstenirse, sistemde elde edilen veriler, daha komplike bir sistemde kullanım için de uygundur.

Gerçekleştirilen çalışma, suyun alındığı ilk rezerv bölgesi dahil, tüm depolama birimlerinde suyun kontrollü olarak dolaşımını sağlamaya yöneliktir. Geliştirilen sistemin benzer sistemlerden farkı, su kaynağı çok uzak bir mesafede de olsa, son kullanıcısına kadar tam otomatik bir biçimde kontrollü akış imkanı sağlayabilmesidir. Çalışma içerisinde yer almamış olsa bile, uzak mesafeler arası kablosuz iletişim imkanları kullanılarak sistemin uygulanabilme imkanı vardır. Sistemin sorunsuz işleyebilmesi için yeterli miktarda su ve elektrik enerjisinin sağlanması şarttır. Sistemde tam otomatik çalışma ile kullanıcıların susuz kalmasının önüne geçildiği gibi, gerekmediğinde akış kesildiğinden su israfı da engellenmiş olmaktadır. Gerçek uygulamalar için sistem çıkışlarında kullanılan röleler yerine kontaktörler kullanılarak AC elektrik motorları tercih edilebilir. Bu durumda kullanılacak AC elektrik motorları, sürücü destekli olarak yumuşak anahtarlamalı yol alacak biçimde tercih edilebilir. Ayrıca, gerçekleştirilen çalışmanın, ilerleyen aşamalarda şehir içme suyu temini ve sulama sistemlerinde su temini noktasında değerlendirilmesi planlanmaktadır.

\section{KAYNAKLAR}

[1] Gregory SO, Atkins GL, "Modular Water Facuet with Automatic Water Supply System" US Patent 4,735,357, 1988

[2] İmal N., Çınar H., (2016) "Dalbudak ve Ring Tipi Şebeke Sistemlerinde Röle Koordinasyonu", İleri Teknoloji Bilimleri Dergisi Cilt 5, Sayı 1

[3] T. Kingham and T. Hoggart, "Chlorination control in a large water treatment works," in IEEE Colloquium on Application of Advanced PLC (Programmable Logic Controller) Systems with Specific Experiences from Water Treatment, pp. 2/1-2/16, June 1995. 
[4] Kaya Z., İmal N., Gökhasan O., (2018),"On power transformers energy efficiency based load transfer analysis" International Journal of Energy Applications and Technologies, e-ISSN: 2548-060X

[5] Lenker J. Carroll J. Lenkor K. Carroll C. (2002). "Method and Apparatus for Water Flow Sensing and Control" US20040128034A1,

[6] Daldal N. (2018). "İçme suyu şebeke otomasyonunun tasarımı ve gerçekleştirilmesi" Pamukkale Üniversitesi Mühendislik Bilimleri Dergisi 24(5), 831-836 doi: 10.5505/pajes.2017.66424

[7] Olsson G. (2007). "Environmental Engineering Research 2007;12(5), Automation Development in Water and Wastewater Systems 197-200. DOI: https://doi.org/10.4491/eer.2007.12.5.197

[8] Olsson G. (2006). "Instrumentation, Control and Automation in the Water Industry - State-of-the-Art and New Challenges" Water Sci Technol 53 (4-5): 1-16.https://doi.org/10.2166/wst.2006.097

[9] Maturanaa F. P. Tichy P. Šlechtab P. Discenzoa F. Starona R. J. Halla K. (2004). "Distributed multi-agent architecture for automation systems" Expert Systems with Applications Volume 26, Issue 1, Pages 49-56

[10] Kastner W. ; Neugschwandtner G. Soucek S. (2005). "Newman H. M. Communication systems for building automation and control" Proceedings of the IEEE, 10.1109/JPROC.2005.849726

[11] Diduck V. J., (1996). "Integrated Local or Remote Control Liquid Gas Leak Detection and Shut-Off System" US6025788A

[12] Vajargah A., Oort E., (2015). "Early Kick Detection And Well Control Decision-Making For Managed Pressure Drilling Automation", Journal of Natural Gas Science and Engineering, Volume 27, Part 1, Pages 354-366, https://doi.org/10.1016/j.jngse.2015.08.067

[13] Das R., Dutta S., Sarkar A., Samanta K., (2013), "PageAutomation of Tank Level Using Plc and Establishment of Hmi by Scada", IOSR Journal of Electrical and Electronics Engineering, Volume 7, Issue 2, PP 61-67.

[14] Brakel J., Tarr B., Cox W., Jorgensen F., Straume H. V., (2015)."Smart Kick Detection: First Step on The Well-Control Automation Journey", Society of Petroleum Engineers, Volume 30, Issue 03.

[15] Kozlu H., Üçgün H., İmal N, (2016)"Arm Modülü Kullanarak Usart Haberleşme", Uluslararası Bilgisayar Bilimleri ve Mühendisliği Konferansı, Tekirdağ.

[16] Di Nardo A., Di Natale M.,; Santonastaso G. F., Tzatchkov V. G., "Water Network Sectorization Based on Graph Theory and Energy Performance Indices", Journal of Water Resources Planning and Management, Volume 140 Issue 5 - May 2014.

[17] Kaya Z., İmal N., Gökhasan O., (2018), "Energy Efficiency Based Load Transfer Transformer Analysis" 7th International Conference on Advanced Technologies, Antalya.

[18] Özkaya U., Ulukut Ö., Çömlekçi S., Vardar G., “İçme Suyu Şebekesi Kontrol Otomasyonu”, III Otomasyon Sempozyumu ve Sergisi, s.54-57, 11-12 Kasım 2005, Pamukkale Üniversitesi, Denizli, Türkiye.

[19] Zulhani Rasin Mohd Rizal Abdullah "Water Quality Monitoring System Using Zigbee Based Wireless Sensor Network", International Journal of Engineering \& Technology IJET Vol: 9 No: 10 91410-7575 IJET-IJENS @ International Journals of Engineering and Sciences IJENS 24. 